Asian J. Med. Biol. Res. 2021, 7 (2), 153-163; doi: 10.3329/ajmbr.v7i2.54995

\author{
Asian Journal of \\ Medical and Biological Research \\ ISSN 2411-4472 (Print) 2412-5571 (Online) \\ www.ebupress.com/journal/ajmbr
}

\title{
Article \\ Dietary effect of moringa (Moringa oleifera; Lamarck, 1785) leaf powder on growth response of tilapia (Oreochromis niloticus; Linnaeus, 1758)
}

\author{
Zubyda Mushtari Nadia ${ }^{1,2}$, Prosun Roy $^{2}$, Sayed Mashequl Bari ${ }^{1}$ and Md. Abdus Salam ${ }^{2 *}$ \\ ${ }^{1}$ Department of Aquatic Animal Health Management, Sher-e-Bangla Agricultural University, Dhaka 1207, \\ Bangladesh \\ ${ }^{2}$ Department of Aquaculture, Bangladesh Agricultural University, Mymensingh 2202, Bangladesh
}

*Corresponding Author: Professor Dr. Md. Abdus Salam, Department of Aquaculture, Bangladesh Agricultural University, Mymensingh 2202, Bangladesh. Phone: +8801711024408; E-mail: salamaqua@ bau.edu.bd

Received: 19 May 2021/Accepted: 23 June 2021/ Published: 30 June 2021

\begin{abstract}
Management of fish health is one of the main considerations in aquaculture and different plant compounds are being used for supporting fish health to minimize the negative impacts of synthetic aqua drugs. In the present experiment, potentiality of moringa (Moringa oleifera; Lamarck, 1785) leaf as a nutritious dietary source for tilapia (Oreochromis niloticus; Linnaeus, 1758) fish was tested and the duration was two months from $30^{\text {th }}$ September to $30^{\text {th }}$ November, 2020. The moringa leaves were brought, cleaned, dried, and finally crushed into powder. Three experimental diets were formulated using the processed moringa leaf powder (MLP) at the rate of $0 \%\left(\mathrm{MLP}_{0 \%}\right)$ as control, $10 \%\left(\mathrm{MLP}_{10 \%}\right)$ and $20 \%\left(\mathrm{MLP}_{20 \%}\right)$ as treatment mixing with rice bran, wheat bran, mustard oil cake, fish meal, soya oil and vitamin-mineral premix. Fifteen tilapia fingerlings having average initial length $10.88 \pm 0.11 \mathrm{~cm}$ and initial weight $29.06 \pm 0.50 \mathrm{~g}$ was stocked in each tank with $90 \mathrm{~L}$ water. Sixty days feeding trial was performed with three replications of each treatment. The fishes were fed with formulated feeds twice daily at 9 am and $4 \mathrm{pm}$ at a rate of $3 \%$ of their body mass. Sampling of fish and water quality parameters were carried out at twelve days interval. Moreover, the blood glucose and cholesterol of tilapia were measured monthly. Final length, final weight, weight gain, percent weight gain, feed conversion ratio (FCR), specific growth rate (SGR) and production of tilapia were significantly different among the treatments. The highest FCR $(3.17 \pm 0.25)$ and SGR $(1.33 \pm 0.12 \%)$ values were in MLP $_{20 \%}$ and MLP M $_{10 \% \text {, }}$ respectively. In the experiment, the highest and the lowest tilapia production were $9.21 \pm 0.39$ and $7.39 \pm 0.35 \mathrm{~kg}$ $\mathrm{m}^{-3}$ in $\mathrm{MLP}_{10 \%}$ and $\mathrm{MLP}_{20 \%}$, respectively. The blood glucose values were significantly different among the treatments $(p<0.05)$ and the highest value was in $\operatorname{MLP}_{0 \%}\left(48.00 \pm 2.00 \mathrm{mg} \mathrm{dl}^{-1}\right)$. Moreover, the highest and the lowest blood cholesterol was found in $\operatorname{MLP}_{0 \%}\left(177.67 \pm 2.52 \mathrm{mg} \mathrm{dl}^{-1}\right)$ and $\mathrm{MLP}_{20 \%}\left(148.33 \pm 1.53 \mathrm{mg} \mathrm{dl}^{-1}\right)$, respectively whereas the values were highly significantly different among the treatments $(p \leq 0.01)$. Water quality parameters were statistically similar among the treatments $(p>0.05)$ and the values were within acceptable range for tilapia culture.
\end{abstract}

Keywords: blood parameter; growth responses; moringa; tilapia; water quality

\section{Introduction}

Fish is a cheap and easily digestible animal protein source significantly contributing to the national food basket of Bangladesh. Aquaculture sector is a major contributor towards fish supply and its rapid development leads to the intensification of the culture practices (Nadia et al., 2021; Srichaiyo et al., 2020). The continuous and uncontrolled intensification of aquaculture creates several health risks of fish such as poor growth, infectious and non-infectious diseases (Hussain et al., 2018). Till now chemotherapy is the only option for prevention and management of aquaculture disease outbreaks which negatively affect the environment and human health (Faruk et al., 2021; Jahan et al., 2021). Hence, in recent years attention is given towards eco-friendly and sustainable 
methods of aquaculture disease management practices using different plants as immune stimulants (Srichaiyo $e t$ al., 2020; Stratev et al., 2018). Many products from the plant origin have been reported to stimulate appetite, promote growth performances, and act as immune-stimulants, antibacterial, antiviral, and anti-parasitic agent in aquaculture (Jahanjoo et al., 2018; Muniruzzaman and Chowdhury, 2008). An application of immune stimulants for the prevention of fish diseases are considered as an attractive and promising area as plants are safer, much more effective and cheaper than the synthetic substances (Yao et al., 2020). Scientists are working to develop low-cost, nutrient-dense feed and to use plant extracts, and natural plant compounds as potential alternatives to synthetic chemicals for stimulating immune responses and disease tolerance in fish (Abdel-Hakim et al., 2010; Reverter et al., 2014). Herbal phytochemicals can boost the innate immune system and have antimicrobial properties that could be very useful in fish farming without causing any environmental or health risks (Jahanjoo et al., 2018; Chakraborty and Hancz, 2011). Such ingredients extracted from plants have antioxidant properties those can upgrade fish's physiological state (Hussain et al., 2018; Zhou et al., 2016). Nutritious diet not only promotes growth of fish but also enhances survival rate which is profitable in case of aquaculture.

Moringa oleifera (Lamarck, 1785) or moringa is one of the most well-known plant species and is the only genus in the Moringaceae family with high crude protein content in the leaves and low tannin and other anti-nutritional compounds (Shourbela et al., 2020; Puycha et al., 2017). Its n-3 fatty acids in the form of linolenic acid account for about 67 percent of total fatty acids in the crude lipid (Hussain et al., 2018). Leaf of Moringa contains significant amount of iron, carotenoids, ascorbic acid, and minerals (Elabd et al., 2019). Moringa leaves are also an excellent source of nutrients such as protein, lipid, and gross energy. According to Puycha et al. (2017), moringa can be considered as a potential source of protein introducing at low amount in fish diet to make aquaculture production cost effective. On the other hand, tilapia (Oreochromis niloticus; Linnaeus, 1758) is considered as the second most important farmed fish in the world, after carps (Toutou et al., 2018; Ronald et al., 2014; Reda et al., 2013). Tilapia culture is practiced in most tropical, subtropical, and temperate regions because it grows quickly, requires little oxygen, can withstand a wide range of temperatures, is disease tolerant, and results in high yield (Nadia et al., 2020; Srichaiyo et al., 2020; Makori et al., 2017). One of the main considerations in aquaculture industry is to reduce feed and production cost. Preparation of fish feed mixed with cheap plant ingredient like moringa leaves can result in low-cost nutrient rich feed and also can reduce the necessity of synthetic drugs. So, the present study is aimed to assess growth parameters of tilapia fed with moringa leaves mixed feed.

\section{Materials and Methods}

\subsection{Experimental design}

The experiment was carried out on a rooftop in Rajbari Sadar sub-district under Rajbari District, Bangladesh (Latitude: $23^{\circ} 36^{\prime} 22.03^{\prime \prime} \mathrm{N}$; Longitude: $89^{\circ} 50^{\prime} 26.30^{\prime \prime} \mathrm{E}$ ). The duration of the study was two months from $30^{\text {th }}$ September to $30^{\text {th }}$ November, 2020. In case of fish rearing, 9 fish holding tanks containing $90 \mathrm{~L}$ of water were used. Throughout the experiment, two air-pump of $18 \mathrm{~W}$ (Resun, Model ACO-001, China) with six nozzles were used to provide dissolved oxygen to the fish tanks, each with two nozzles with perforated stones whereas the aeration was maintained for 24 hours. Three experimental diets were made for the fish using moringa leaf powder that was processed at the rate of $0 \%, 10 \%$ and $20 \%$ denoting as $\mathrm{MLP}_{0 \%}, \mathrm{MLP}_{10 \%}$ and $\mathrm{MLP}_{20 \%}$, respectively (Table 1). The experiment was designed out with three replications for each treatment.

\subsection{Feed preparation with moringa leaf powder}

Moringa leaves were collected from moringa plant and after collection; the leaves were separated from the stems and dried under sunlight. When the moringa leaves were crispy, they were crushed into small pieces by hand and then finely powdered in blenders. The ingredients for the fish feed were purchased from local market including rice bran, wheat bran, mustard oil cake, fish meal, soya oil and vitamin-mineral premix. All the dietary ingredients were crushed finely and manually sieved thoroughly to obtain a homogenous mixture following Rana et al. (2020). To adjust the ingredients amount, rice bran and wheat bran were partially replaced with moringa leaf powder (MLP) in case of $\mathrm{MLP}_{10 \%}$ and $\mathrm{MLP}_{20 \%}$. Using an electronic balance (Electronic Precision Balance, EK 600i), all ingredients, including vitamins and minerals premixes were weighted according to the composition of experimental diets (Table 1). The ingredients were mixed well, and water was used to moisten the mixture. The resulting dough was pressed through pelleting machine using $1 \mathrm{~mm}$ meshed sieve. The formulated pellets were sun dried, broken into small pieced and stored in airtight plastic container. 
Table 1. Amount of feed ingredients used in the test diets for tilapia.

\begin{tabular}{|c|c|c|c|}
\hline \multirow{2}{*}{ Feed ingredients } & \multicolumn{3}{|c|}{ Amount of feed ingredients in $\mathrm{g}$} \\
\hline & $\mathbf{M L P}_{\mathbf{0} \%}$ & $\mathbf{M L P}_{10 \%}$ & $\mathbf{M L P}_{20 \%}$ \\
\hline Moringa leaf powder & 0 & 10 & 20 \\
\hline Rice bran & 20 & 15 & 10 \\
\hline Wheat bran & 20 & 15 & 10 \\
\hline Mustard oil cake & 25 & 25 & 25 \\
\hline Fish meal & 30 & 30 & 30 \\
\hline Soya oil & 3 & 3 & 3 \\
\hline Vitamin mineral premix & 2 & 2 & 2 \\
\hline
\end{tabular}

Here, $\mathrm{MLP}_{0 \%}=$ Feed with $0 \%$ moringa leaf powder (control); $\mathrm{MLP}_{10 \%}=$ Feed with $10 \%$ moringa leaf powder and $\mathrm{MLP}_{20 \%}=$ Feed with $20 \%$ moringa leaf powder.

\subsection{Tilapia stocking and rearing}

Tilapia fingerlings were brought from the Elem Fish Farm which is located in the Rajbari Sadar sub-district under Rajbari district, Bangladesh. After collection, fishes were acclimatized for 7 days in the culture tank to release the stress during transportation and for adapting with new environmental conditions. Fifteen tilapia fingerlings with average weight $29.06 \pm 0.50 \mathrm{~g}$ was allocated randomly in each tank. Throughout the experiment, fishes were fed with experimental diets twice a day at $9 \mathrm{am}$ and $4 \mathrm{pm}$ at a rate of $3 \%$ of their body weight. The uneaten feed and feces were removed with $14^{\text {th }}$ water exchange daily through siphoning and the entire water was changed fortnightly with fresh underground water.

\subsection{Sampling of tilapia}

Fishes were caught using a scope net for sampling and the fishes were sampled at twelve days interval during study. The length and weight of fish from each tank were measured using a measuring scale and an electronic balance. To test the growth efficiency of tilapia, several parameters were calculated namely length gain, weight gain, percent length gain, percent weight gain, specific growth rate (SGR), feed conversion ratio (FCR), survival rate and production according to Moniruzzaman et al. (2015).

\subsection{Blood parameters}

Blood glucose and cholesterol of tilapia were measured thrice during experiment at 30 days interval and initiated from $30^{\text {th }}$ September, 2020. The values of blood glucose and cholesterol were determined using an 'Easy Touch GCHb Meter, Bioptik Technology, Taiwan' where the minimum requirements for blood analysis are $4 \mu \mathrm{l}$ and $15 \mu \mathrm{l}$, respectively. Aketch et al. (2014), Zang et al. (2013) and Beecham et al. (2011) also utilized handheld portable blood meter for testing fish blood. During blood test, five fishes from each tank were randomly caught and blood was collected through caudal venipuncture. Green test stripe of the blood meter was used for glucose determination while blue colored test stripe was for cholesterol test. The stripes were attached to the stripe slot of the device during test. Collected blood was put on the mark of stripe and the result came out on the screen. After blood collection through injection, the blood test was done immediately as clotted blood does not provide result and then the fishes were released in their specific tanks.

\subsection{Water quality parameters of fish tanks}

Water temperature, dissolved oxygen (DO), $\mathrm{pH}$, electrical conductivity (EC) and total dissolved solids (TDS) were measured at twelve days interval using a thermometer, a Lutron Dissolved Oxygen meter PDO-519, Hanna HI-98107 pH Meter and E-1 portable EC-TDS meter, respectively. The water quality parameters were measured at 10 am of the sampling date throughout the experiment.

\subsection{Data processing and analysis}

The data were statistically analyzed for variance and one-way ANOVA using SPSS 20.00 (Statistical Package for Social Sciences) and significant differences among the mean values of the treatments were compared using Duncan's Multiple Range Test (DMRT) considering 5 and $1 \%$ level of probability. 
3. Results and Discussion

\subsection{Growth performances of tilapia}

3.1.1. Length gain and percent length gain of tilapia

The initial mean length of tilapia was $10.84 \pm 1.49,11.02 \pm 0.80$ and $10.80 \pm 1.07 \mathrm{~cm}$ in $\mathrm{MLP}_{0 \%}, \mathrm{MLP}_{10 \%}$ and $\mathrm{MLP}_{20 \%}$, respectively those were increased up to $14.60 \pm 0.25,14.92 \pm 0.11$ and $14.58 \pm 0.19 \mathrm{~cm}$ in $\mathrm{MLP}_{0 \%}$, MLP $_{10 \%}$ and $\mathrm{MLP}_{20 \%}$, respectively. During $18^{\text {th }}$ November, 2020 and $30^{\text {th }}$ November, the length of tilapia was significantly different $(p<0.05)$ among the treatments, whereas there was no significant difference in mean length gain among the treatments (Figure 1). The values of percent length gain of tilapia were $34.78 \pm 0.30$, $38.84 \pm 5.53$ and $35.24 \pm 0.95 \%$ in MLP $_{0 \%}$, MLP $_{10 \%}$ and MLP $_{20 \%}$, respectively. Higher length gain in MLP $10 \%$ than $\mathrm{MLP}_{0 \%}$ and $\mathrm{MLP}_{20 \%}$ might be due to the efficient diet of MLP $10 \%$ for tilapia (Table 2). Nadia et al. (2020) reported that, the mean length gain and percent length gain of tilapia were $4.74 \pm 0.67 \mathrm{~cm}$ and $61.46 \pm 0.44 \%$, respectively over a period of 106 days. Moreover, Roy et al. (2021) recorded percent length gain of tilapia ranging from $24.01 \pm 3.26$ to $26.84 \pm 2.65 \%$ over a period of 93 days.

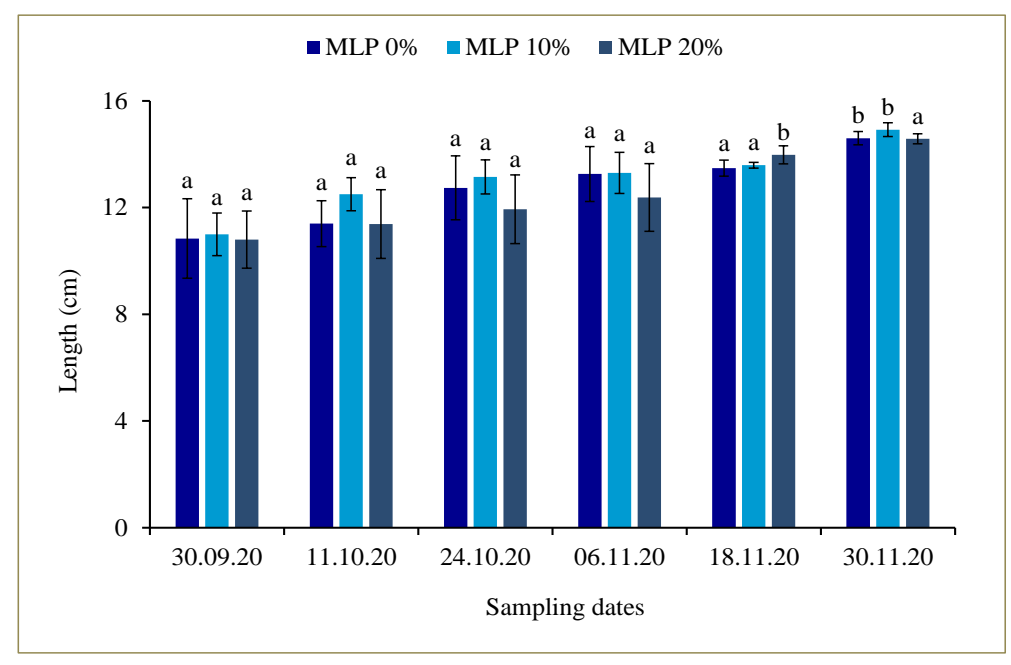

Figure 1. Length of tilapia in different sampling dates. Here, vertical bar of each treatment represents standard deviation; bars with different letters are significantly different at $p \leq 0.05$ applying Duncan's Multiple Range Test (DMRT) and similar letters indicate non-significance where $p>0.05$.

\subsubsection{Weight gain and percent weight gain of tilapia}

Fish weight during last three sampling showed significant differences among the treatments (Figure 2). The highest and the lowest mean final weight were $60.68 \pm 3.05$ and $53.90 \pm 2.09 \mathrm{~g}$ in $\mathrm{MLP}_{10 \%}$ and $\mathrm{MLP}_{0 \%}$, respectively, whereas the mean weight gain of tilapia were $25.63 \pm 0.42,31.89 \pm 0.57$ and $27.46 \pm 0.76 \mathrm{~g}$ in $\mathrm{MLP}_{0 \%}$, $\mathrm{MLP}_{10 \%}$ and $\mathrm{MLP}_{20 \%}$, respectively and the values were highly significantly different $(p \leq 0.01)$ among the treatments (Table 2). The highest percent weight gain was in $\operatorname{MLP}_{10 \%}(103.70 \pm 4.38 \%)$ followed by MLP $_{0 \%}$ $(92.53 \pm 0.99 \%)$ and $\mathrm{MLP}_{20 \%}(89.22 \pm 0.89 \%)$, respectively and the values were lower than the findings of Nadia et al. (2020) and Moniruzzaman et al. (2015). Moreover, Nassar et al. (2021) found $16.92 \pm 0.21$ to $20.75 \pm 0.19 \mathrm{~g}$ weight gain after 97 days. Nirmala et al. (2020) opined that, fish growth is influenced by internal and external factors like disease resistance, feed availability and culture system.

\subsubsection{Specific growth rate (SGR) of tilapia}

In the present experiment, the highest and the lowest SGR were $1.33 \pm 0.12$ and $1.07 \pm 0.03 \%$ in $\mathrm{MLP}_{10 \%}$ and $\mathrm{MLP}_{0 \%}$, respectively (Table 2). Moreover, the values were highly significantly different among the treatments ( $p \leq 0.01$ ). Makori et al. (2017) found higher SGR (2.03-2.34\%) than the present study feeding fish with commercial feed at $10 \%$ body weight rearing at pond. It might be due to more favorable water quality in pond than tank culture system. During cage culture of tilapia, Moniruzzaman et al. (2015) noted SGR ranging from 2.02 to $2.35 \%$ in 120 days. 


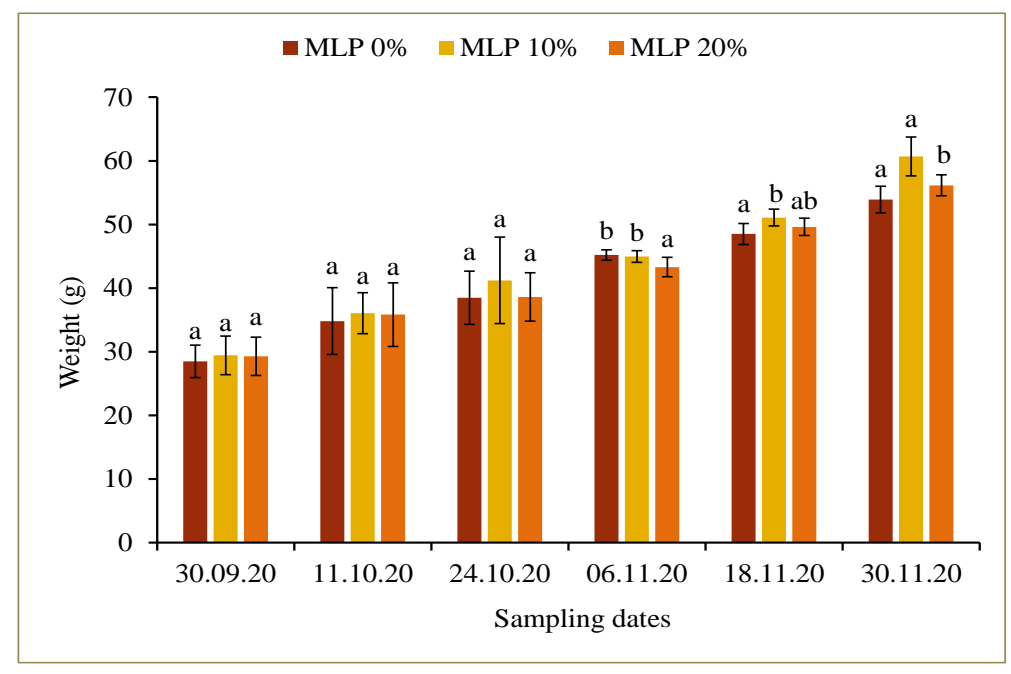

Figure 2. Weight of tilapia in different sampling dates. Here, vertical bar of each treatment represents standard deviation; bars with different letters are significantly different at $p \leq 0.05$ applying Duncan's Multiple Range Test (DMRT) and similar letters indicate non-significance where $p>0.05$.

\subsubsection{Feed conversion ratio (FCR) of tilapia}

FCR is useful to determine the fish ability to digest feed and it shows the amount of feed used to increase fish weight by $1 \mathrm{~kg}$. The FCR values of tilapia were $2.73 \pm 0.21,2.60 \pm 0.17$ and $3.17 \pm 0.25$ in MLP $_{0 \%}$, MLP $_{10 \%}$ and MLP $_{20 \%}$, respectively (Table 2). Higher FCR in $\mathrm{MLP}_{20 \%}$ might be due to the wastage of feed and less attraction to the formulated feed with $20 \%$ moringa leaf powder which might be due to the omnivorous nature of tilapia. According to Nirmala et al. (2020), FCR is influenced by several factors namely species, size, quality, and quantity of feed as well as the water quality that will determine the feed effectiveness. Nadia et al. (2020) found FCR 3.2 \pm 0.11 over a period of 106 days where they supplied commercial floating feed at the similar rate of the present study. However, low FCR value in $\mathrm{MLP}_{10 \%}$ in the present study indicated high fish efficiency in utilizing the feed consumed. Akter et al. (2020) reported similar FCR (2.98 to 3.68) to the present study where they reared tilapia in tank.

\subsubsection{Survival rate of tilapia}

In the current study, the highest survival rate of tilapia was in $\mathrm{MLP}_{10 \%}(91.00 \pm 3.46 \%)$, followed by $\mathrm{MLP}_{0 \%}$ $(82.22 \pm 13.61 \%)$ and $\mathrm{MLP}_{20 \%}(80.10 \pm 7.51 \%)$, respectively (Table 2). The lowest survival rate in MLP $20 \%$ might be due to improper growth and less ingestion of nutritious feed. But the survival rates were not significantly influenced by the treatments ( $p>0.05)$. Survival rate of tilapia reported by Moniruzzaman et al. (2015) (90.93\%) and Abdel-Hakim et al. (2010) (85.19\%) were in line with the present study. Makori et al. (2017) and Toutou et al. (2018) found survival rate ranging from $78.43 \pm 1.96$ to $84.31 \pm 1.96 \%$ and $72.59 \pm 5.20$ to $77.50 \pm 1.44 \%$, respectively those were close to the present study. The survival rate of tilapia noted by Akter et al. (2020) (66.66 to $76.66 \%$ in 60 days) was lower than the present study where they utilized commercial floating feed. The outcome of the present study indicates that, moringa leaf powder mixed feed is more effective to increase survival rate of fish than the commercial feed.

\subsubsection{Tilapia production}

Profit from aquaculture mostly depends on fish production which depends on fish growth and suitability of the culture system. The highest fish production was $9.21 \pm 0.39 \mathrm{~kg} \mathrm{~m}^{-3}$ in $\mathrm{MLP}_{10 \%}$ followed by $\mathrm{MLP}_{0 \%}(7.49 \pm 0.63)$ and $\mathrm{MLP}_{20 \%}(7.39 \pm 0.25) \mathrm{kg} \mathrm{m}^{-3}$ (Table 2). Fish production was significantly different among the treatments $(p<$ $0.05)$ which indicate that addition of $10 \%$ moringa leaf powder $\left(\mathrm{MLP}_{10 \%}\right)$ in feed has high potential than the other treatments. Moniruzzaman et al. (2015) found 12.4 to $18.8 \mathrm{~kg} \mathrm{~m}^{-3}$ monosex tilapia over a period of 120 days in cage culture system in Kaptai Lake which was higher than the present study and it might be due to the open water condition. 
Table 2. Growth performance of tilapia feeding with formulated feed in the present study.

\begin{tabular}{lllll}
\hline Parameters & MLP $_{\mathbf{0} \%}$ & MLP $_{\mathbf{1 0} \%}$ & MLP $_{\mathbf{2 0} \%}$ & $\boldsymbol{p}$ value \\
\hline Initial length $(\mathrm{cm})$ & $10.84 \pm 1.49 \mathrm{a}$ & $11.02 \pm 0.80 \mathrm{a}$ & $10.80 \pm 1.07 \mathrm{a}$ & 0.950 \\
Final length $(\mathrm{cm})$ & $14.60 \pm 0.25 \mathrm{~b}$ & $14.92 \pm 0.11 \mathrm{~b}$ & $14.58 \pm 0.19 \mathrm{a}$ & 0.030 \\
Length gain $(\mathrm{cm})$ & $3.72 \pm 0.05 \mathrm{a}$ & $3.83 \pm 0.12 \mathrm{a}$ & $3.77 \pm 0.02 \mathrm{a}$ & 0.224 \\
Percent length gain $(\%)$ & $34.78 \pm 0.30 \mathrm{a}$ & $38.84 \pm 5.53 \mathrm{a}$ & $35.24 \pm 0.95 \mathrm{a}$ & 0.326 \\
Initial weight (g) & $28.49 \pm 2.75 \mathrm{a}$ & $29.43 \pm 3.03 \mathrm{a}$ & $29.27 \pm 3.00 \mathrm{a}$ & 0.863 \\
Final weight (g) & $53.90 \pm 2.09 \mathrm{a}$ & $60.68 \pm 3.05 \mathrm{a}$ & $56.14 \pm 1.65 \mathrm{~b}$ & 0.002 \\
Weight gain $(\mathrm{g})$ & $25.63 \pm 0.42 \mathrm{a}$ & $31.89 \pm 0.57 \mathrm{c}$ & $27.46 \pm 0.76 \mathrm{~b}$ & 0.000 \\
Percent weight gain (\%) & $92.53 \pm 0.99 \mathrm{a}$ & $103.70 \pm 4.38 \mathrm{~b}$ & $89.22 \pm 0.89 \mathrm{a}$ & 0.001 \\
FCR & $2.73 \pm 0.21 \mathrm{a}$ & $2.60 \pm 0.17 \mathrm{a}$ & $3.17 \pm 0.25 \mathrm{~b}$ & 0.040 \\
SGR $(\%)$ & $1.20 \pm 0.03 \mathrm{ab}$ & $1.33 \pm 0.12 \mathrm{~b}$ & $1.07 \pm 0.03 \mathrm{a}$ & 0.012 \\
Survival rate $(\%)$ & $82.22 \pm 13.61 \mathrm{a}$ & $91.00 \pm 3.46 \mathrm{a}$ & $80.10 \pm 7.51 \mathrm{a}$ & 0.120 \\
Production $\left(\mathrm{kg} \mathrm{m}^{-3}\right)$ & $7.49 \pm 0.63 \mathrm{a}$ & $9.21 \pm 0.39 \mathrm{~b}$ & $7.39 \pm 0.35 \mathrm{a}$ & 0.005 \\
\hline
\end{tabular}

Here, $\mathrm{MLP}_{0 \%}=$ Feed with $0 \%$ moringa leaf powder (control); $\mathrm{MLP}_{10 \%}=$ Feed with $10 \%$ moringa leaf powder and $\mathrm{MLP}_{20 \%}=$ Feed with $20 \%$ moringa leaf powder. Means $( \pm$ SD) were calculated from three replicates for each treatment. Bars with different letters are significantly different at $p \leq 0.05$ applying Duncan's Multiple Range Test (DMRT) and similar letters indicate non-significance where $p>0.05$.

\subsection{Tilapia blood parameters}

\subsubsection{Glucose}

In the present study, the glucose concentrations of tilapia blood were $48.00 \pm 2.00,44.33 \pm 1.53$ and $43.67 \pm 1.53$ $\mathrm{mg} \mathrm{dl}^{-1}$ in $\mathrm{MLP}_{0 \%}, \mathrm{MLP}_{10 \%}$ and $\mathrm{MLP}_{20 \%}$, respectively and there were significant differences $(p<0.05)$ in glucose concentrations among the treatments (Table 3). Glucose is one of the most important energy sources used by fish to cope up with physiological stress. Increase in blood glucose levels is responsible for provision of energy that is used by fish to adjust with stress. In the present study, the lowest glucose in MLP $_{20 \%}$ (Figure 3) might be due to the utilization of glucose as a result of stress resulting from temperature fluctuation. Toutou et al. (2018) noted that, dietary supplementation of lemon peel decreased the blood glucose level. Jimoh et al. (2015) reported that diet of tilapia containing watermelon seed meal resulted no significant change in blood glucose level.

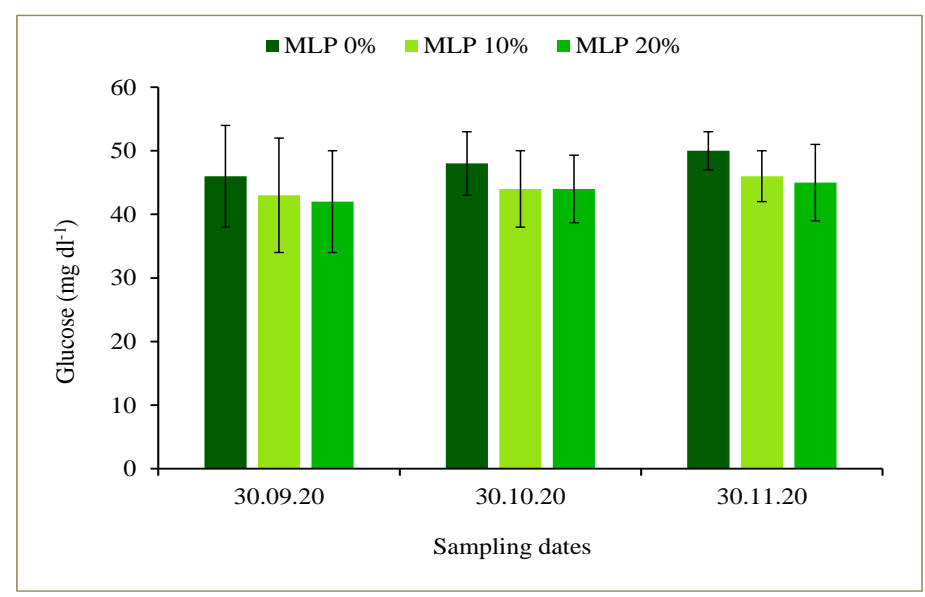

Figure 3. Blood glucose of tilapia in different sampling dates (vertical bar of each treatment represents standard deviation).

\subsubsection{Cholesterol}

Moreover, the blood cholesterol values of tilapia were $177.67 \pm 2.52,152.67 \pm 2.08$, and $148.33 \pm 1.53 \mathrm{mg} \mathrm{dl}^{-1}$ in $\mathrm{MLP}_{0 \%}, \mathrm{MLP}_{10 \%}$ and $\mathrm{MLP}_{20 \%}$, respectively and there were highly significantly differences $(p \leq 0.01)$ among the treatments (Table 3). The concentration of blood cholesterol is influenced by the fat content in the diet and is an important blood component to evaluate new diets. At the end of experiment, the value of blood cholesterol in MLP $_{20 \%}$ was lower than MLP $_{0 \%}$ and MLP $_{20 \%}$. The highest cholesterol value was $180 \mathrm{mg} \mathrm{dl}^{-1}$ in $\mathrm{MLP}_{0 \%}$ on $30^{\text {th }}$ November, 2020 (Figure 4). The finding of Nirmala et al. (2020) was in line with the present study where the 
cholesterol value of red tilapia ranged from 134.85 to $184.57 \mathrm{mg} \mathrm{dl}^{-1}$. Yao et al. (2020) opined that, lotus leaf extract in feed lowers the blood cholesterol level significantly in tilapia.

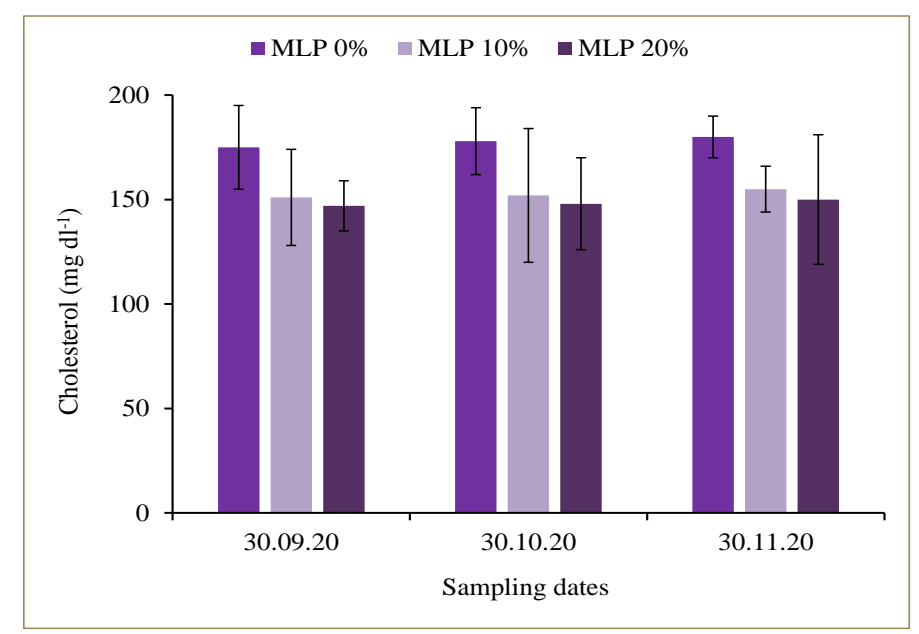

Figure 4. Blood cholesterol of tilapia in different sampling dates (vertical bar of each treatment represents standard deviation).

Table 3. Effect of moringa leaf powder on blood glucose and cholesterol of tilapia.

\begin{tabular}{lllll}
\hline Parameters & MLP $_{\mathbf{0}}$ & MLP $_{\mathbf{1 0} \%}$ & MLP $_{\mathbf{2 0} \%}$ & $\boldsymbol{p}$ value \\
\hline Glucose $\left(\mathrm{mg} \mathrm{dl}^{-1}\right)$ & $48.00 \pm 2.00 \mathrm{~b}$ & $44.33 \pm 1.53 \mathrm{a}$ & $43.67 \pm 1.53 \mathrm{a}$ & 0.042 \\
Cholesterol $\left(\mathrm{mg} \mathrm{dl}^{-1}\right)$ & $177.67 \pm 2.52 \mathrm{c}$ & $152.67 \pm 2.08 \mathrm{~b}$ & $148.33 \pm 1.53 \mathrm{a}$ & 0.000 \\
\hline
\end{tabular}

Here, $\mathrm{MLP}_{0 \%}=$ Feed with $0 \%$ moringa leaf powder (control); $\mathrm{MLP}_{10 \%}=$ Feed with $10 \%$ moringa leaf powder and $\mathrm{MLP}_{20 \%}=$ Feed with $20 \%$ moringa leaf powder. Means $( \pm$ SD) were calculated from three replicates for each treatment. Bars with different letters are significantly different at $p \leq 0.05$ applying Duncan's Multiple Range Test (DMRT).

\subsection{Water quality parameters}

\subsubsection{Temperature}

Water temperature is a very crucial parameter for fish to maintain normal physiological process in body and it strongly affects aquaculture production (Akter et al., 2020; Boyd, 2017). During present experiment, the water temperature was fluctuated throughout the study ranging from 23.54 to $31.17^{\circ} \mathrm{C}$ (Figure 5a) and the mean values were statistically similar among the treatments $(p>0.05)$ (Table 4). Water temperature in all the treatments increased up to $24^{\text {th }}$ October, 2020 and after that downward trend of temperature was found up to the $30^{\text {th }}$ November, 2020 (Figure 5a). Sudden fluctuation in water temperature might have reduced the survival rate and appeal for feed of the stock. The temperature range of the present study was suitable for aquaculture (Abdelrahman and Boyd, 2018; Boyd, 1990) and the values were close to the finding of Nirmala et al. (2020) whereas they found $28.07-30.60^{\circ} \mathrm{C}$ during an experiment of tilapia after using phytochemical. According to Handayani et al. (2013), the optimum temperature range for the cultivation of tilapia was $25-30^{\circ} \mathrm{C}$.

\subsubsection{Dissolved oxygen (DO)}

The mean values of dissolved oxygen (DO) were 5.18 $\pm 0.60,5.24 \pm 0.53$ and $4.93 \pm 0.53 \mathrm{mg} \mathrm{L}^{-1}$ in $\mathrm{MLP}_{0 \%}$, MLP $_{10 \%}$ and MLP $20 \%$, respectively (Table 4). During study, the lowest DO $\left(4.27 \mathrm{mg} \mathrm{L}^{-1}\right)$ was observed on $30^{\text {th }}$ November, 2020 in $\mathrm{MLP}_{20 \%}$ (Figure 5b). The DO concentrations were not significantly different among the treatments $(p>0.05)$ (Table 4) which might be due to suitable stocking density in the rearing tanks and regular siphoning of the excreta and uneaten feed from the bottom. Makori et al. (2017) found DO $10.6 \pm 8.4 \mathrm{mg} \mathrm{L}^{-1}$ during tilapia culture. Akter et al. (2020) reported that, continuous use of air pump during fish culture enhances dissolved oxygen which increased up to $8.2 \mathrm{mg} \mathrm{L}^{-1}$.

\subsection{3. $\mathrm{pH}$}

The highest and the lowest $\mathrm{pH}$ values were $7.67 \pm 0.42$ and $7.42 \pm 0.40$ in $\mathrm{MLP}_{20 \%}$ and $\mathrm{MLP}_{0 \%}$, respectively and the mean values were statistically similar among the treatments $(p>0.05)$ (Table 4). The highest $\mathrm{pH}(8.20)$ was 
in $\mathrm{MLP}_{10 \%}$ during $30^{\text {th }}$ November, 2020 (Figure 5c). A study by Nirmala et al. (2020) showed that, the pH value during the rearing of red tilapia ranged from 6.88 to 7.91 . Whereas, Handayani et al. (2013) stated that the optimum $\mathrm{pH}$ range for the tilapia culture was 6.5-8.5.

\subsubsection{Electrical conductivity (EC)}

In the experiment, the EC values were fluctuated from 569.02 (in MLP $_{20 \%}$ on $30^{\text {th }}$ September, 2020) to 775.15 $\mu \mathrm{s} \mathrm{cm}^{-1}$ (in $\mathrm{MLP}_{10 \%}$ on $18^{\text {th }}$ November, 2020) (Figure 5d). No significant differences of the EC values were found among the treatments $(p>0.05)$. Stone and Thomforde (2004) mentioned that the desirable range of EC $100-2000 \mu \mathrm{s} \mathrm{cm}^{-1}$ and acceptable range $30-5000 \mu \mathrm{s} \mathrm{cm}^{-1}$ for pond fish culture. Nadia et al. (2020) found that, EC of underground freshwater used for culture was $747.0 \mu \mathrm{s} \mathrm{cm}^{-1}$. Moreover, Akter et al. (2020) found noted $1302.33 \pm 187.79$ to $1521.00 \pm 59.40 \mu \mathrm{s} \mathrm{cm}^{-1}$ during an experiment of aquaponics using tilapia.

\subsubsection{Total dissolved solids (TDS)}

The mean values of TDS were $355.17 \pm 23.52$, 352.50 \pm 19.44 and $365.83 \pm 14.96 \mathrm{mg} \mathrm{L}^{-1}$ in $\mathrm{MLP}_{0 \%}, \mathrm{MLP}_{10 \%}$ and $\mathrm{MLP}_{20 \%}$, respectively. The values were statistically similar among the treatments (Table 4) which might be due to the regular siphoning of the waste materials from the tanks. However, the TDS of the present study (Figure 5e) was lower than the result of Khan et al. (2017) where they reported TDS of 653-740 mg L $\mathrm{L}^{-1}$ during pond culture. Roy et al. (2021) observed water TDS during tilapia culture ranging from $188.36 \pm 36.45$ to $249.51 \pm 57.12 \mathrm{mg} \mathrm{L}^{-1 .}$
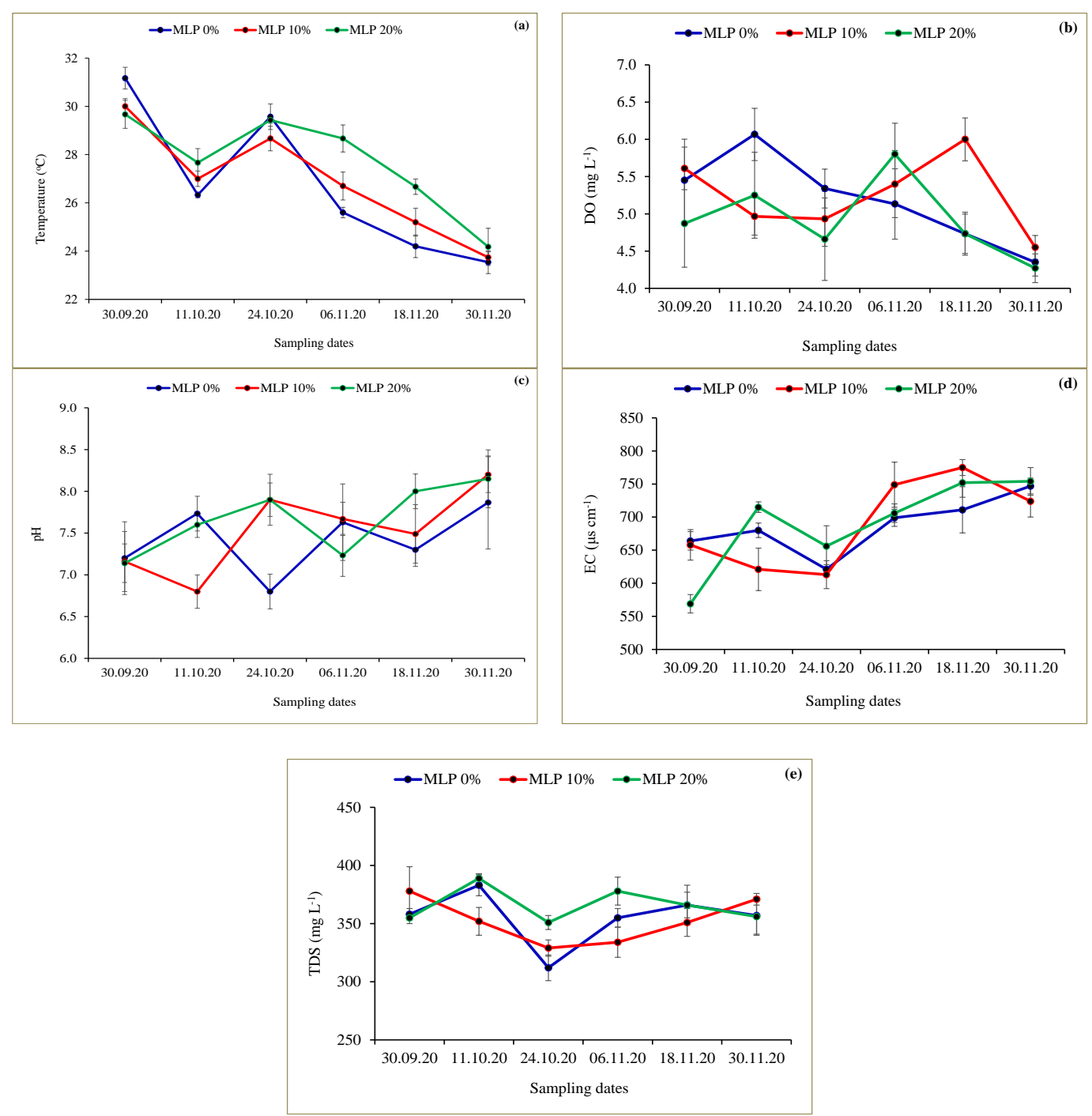

Figure 5. (a) Water temperature (b) DO (c) pH (d) EC (e) TDS in three treatments throughout the experiment and symbols (dots) represent measured values on different sampling dates. 
Table 4. Water quality parameters of fish tanks in three treatments during present experiment.

\begin{tabular}{lllll}
\hline Parameters & $\mathbf{M L P}_{\mathbf{0} \%}$ & $\mathbf{M L P}_{\mathbf{1 0} \%}$ & $\mathbf{M L P}_{\mathbf{2 0} \%}$ & $\boldsymbol{p}$ value \\
\hline Water temperature $\left({ }^{\circ} \mathrm{C}\right)$ & $26.74 \pm 3.03 \mathrm{a}$ & $26.89 \pm 2.27 \mathrm{a}$ & $27.72 \pm 2.06 \mathrm{a}$ & 0.767 \\
DO $\left(\mathrm{mg} \mathrm{L}^{-1}\right)$ & $5.18 \pm 0.60 \mathrm{a}$ & $5.24 \pm 0.53 \mathrm{a}$ & $4.93 \pm 0.53 \mathrm{a}$ & 0.595 \\
pH & $7.42 \pm 0.40 \mathrm{a}$ & $7.54 \pm 0.51 \mathrm{a}$ & $7.67 \pm 0.42 \mathrm{a}$ & 0.632 \\
EC $\left(\mu \mathrm{s} \mathrm{cm}^{-1}\right)$ & $687.00 \pm 43.02 \mathrm{a}$ & $690.00 \pm 68.67 \mathrm{a}$ & $692.00 \pm 70.13 \mathrm{a}$ & 0.990 \\
TDS $\left(\mathrm{mg} \mathrm{L}^{-1}\right)$ & $355.17 \pm 23.52 \mathrm{a}$ & $352.50 \pm 19.44 \mathrm{a}$ & $365.83 \pm 14.96 \mathrm{a}$ & 0.478 \\
\hline
\end{tabular}

Here, $\mathrm{MLP}_{0 \%}=$ Feed with $0 \%$ moringa leaf powder (control); $\mathrm{MLP}_{10 \%}=$ Feed with $10 \%$ moringa leaf powder and $\mathrm{MLP}_{20 \%}=$ Feed with $20 \%$ moringa leaf powder. Means $( \pm$ SD) were calculated from three replicates for each treatment. Similar letters indicate non-significance where $p>0.05$ applying Duncan's Multiple Range Test (DMRT).

\section{Conclusions}

The present study has successfully developed moringa leaf powder-based fish feed for supporting fish growth by lowering the feed cost. Incorporation of moringa leaf power in fish resulted in significant effect on fish growth. Moreover, the water quality parameters did not significantly influence the fish growth and production but were suitable for tilapia. The aqua farmers who supply homemade feed completely or partially, they can also prepare such nutritious feed with minimum cost, and it will increase fish production. So, based on above findings, it can be concluded that, moringa leaf powder is nutritious and if fish feed is formulated maintaining optimum amount for the culture species can boost up the fish production cost effectively which is very important for the small aqua enterprises.

\section{Conflict of interest}

None to declare.

\section{References}

Abdel-Hakim NF, MME Lashin, Al-Azab, AM AL-Desoki and AM Ashry, 2010. Effect of fresh or dried garlic as a natural feed supplement on growth performance and nutrients utilization of the Nile tilapia (Oreochromis niloticas). Egypt. J. Aquat. Biol. Fish., 14: 19-38.

Abdelrahman HA and CE Boyd, 2018. Effects of mechanical aeration on evaporation rate and water temperature in aquaculture ponds. Aquac. Res., 49: 2184-2192.

Aketch BO, PO Ang'ienda, JO Radull and EN Waindi, 2014. Effect of stocking density on the expression of glucose transporter protein 1 and other physiological factors in the Lake Victoria Nile tilapia, Oreochromis niloticus (L.). Int. Aquat. Res., 6: 69.

Akter S, AL Bablee, KMS Rana, M Nigar, ZM Nadia and MA Salam, 2020. Effects of foliar and root application of epsom salt on aquaponics beetroot (Beta vulgaris) production in confined condition. Asian J. Med. Biol. Res., 6: 56-66.

Beecham RV, BC Small and CD Minchew, 2011. Using portable lactate and glucose meters for catfish research: Acceptable alternatives to established laboratory methods? N. Am. J. Aquac., 68, 291-295.

Boyd CE, 1990. Water quality in ponds for aquaculture. Auburn University, Auburn, Alabama, USA. pp. 482.

Boyd CE, 2017. General relationship between water quality and aquaculture performance in Ponds. In Fish Diseases; Academic Press. pp. 147-166.

Chakraborty SB and C Hancz, 2011. Application of phytochemicals as immunostimulant, antipathogenic and antistress agents in finfish culture. Rev. Aquac., 3: 103-119.

Elabd H, E Soror, A El-Asely, EA El-Gawad and A Abbass, 2019. Dietary supplementation of Moringa leaf meal for Nile tilapia Oreochromis niloticus: Effect on growth and stress indices. Egypt. J. Aquat. Res., 45: 265-271.

Faruk MAR, HK Shorna and IZ Anka, 2021. Use and impact of veterinary drugs, antimicrobials, and supplements in fish health management. J. Adv. Vet. Anim. Res., 8: 36-43.

Handayani DI, RE Prihartono, T Afiati, RD Hutasoit, P Raharjo, S Hastuti, Amirudin, D Junaedi and Sudiana, 2013. Pemantauan pembenihan ikan air tawar. J. Budidaya Air Tawar, 9: 61-77. 
Hussain SM, MZH Arsalan, A Javid, AI Hussain, N Aslam, Q Ali, M Hussain, MMH Rehan, MM Shahzad, A Khalid and D Riaz, 2018. Replacement of fish meal with Moringa oleifera leaf meal (MOLM) and its effect on growth performance and nutrient digestibility in Labeo rohita fingerlings. Pak. J. Zool., 50: 1815-1823.

Jahan F, MAR Faruk and KN Azad, 2021. Use of extra-label drugs in commercial aquaculture. J. Bangladesh Agril. Univ., 19: 160-167.

Jahanjoo V, M Yahyavi, R Akrami and AH Bahri, 2018. Influence of adding garlic (Allium sativum), ginger (Zingiber officinale), thyme (Thymus vulgaris) and their combination on the growth performance, haematoimmunological parameters and disease resistance to Photobacterium damselae in sobaity sea bream (Sparidentex hasta) fry. Turkish J. Fish. Aquat. Sci., 18: 633-645.

Jimoh WA, MO Shittu, AA Ayeloja, FO Ajasin, FY Okemakin, SA Abdusalami and OF Adekunle, 2015. Some haematological and biochemical profile of blood of Nile tilapia (Oreochromis niloticus) fed on diets containing watermelon (Citrullus lanatus) seedmeal. Bayero J. Pure Appl. Sci., 8: 109-114.

Khan W, A Vahab, A Masood and N Hasan, 2017. Water quality requirements and management strategies for fish farming (A case study of ponds around Gurgaon Canal Nuh Palwal). Int. J. Trend Res. Dev., 2: 388-393.

Makori AJ, PO Abuom, R Kapiyo, DN Anyona and GO Dida, 2017. Effects of water physico-chemical parameters on tilapia (Oreochromis niloticus) growth in earthen ponds in Teso North Sub-County, Busia County. Fish. Aquat. Sci., 20: 30.

Moniruzzaman M, KB Uddin, S Basak, Y Mahmud, M Zaher and SC Bai, 2015. Effects of stocking density on growth, body composition, yield and economic returns of mono-sex tilapia (Oreochromis niloticus L.) under cage culture system in Kaptai Lake of Bangladesh. J. Aquac. Res. Dev., 6: 357-363.

Muniruzzaman M and MBR Chowdhury, 2008. Evaluation of medicinal plants through fish feed against bacterial fish disease. Progress. Agric., 19: 151-159.

Nadia ZM, P Roy and MA Salam, 2020. Production potential of broccoli (Brassica oleracea var. italica) in hydroponics and tilapia-based aquaponics. J. Bangladesh Agril. Univ., 18: 768-778.

Nadia ZM, P Roy and T Rahman, 2021. Culture practices and health management issues in selected aquafarms of Rajbari, Bangladesh: A preliminary study. J. Food Agric. Environ., 2: 109-116.

Nassar SA, AGA Hassan, MF Badran and MM Abdel-Rahim, 2021. Effects of salinity level on growth performance, feed utilization, and chromatic deformity of the hybrid Red tilapia, Oreochromis niloticus x $O$. mossambicus. Egypt. J. Aquat. Biol. Fish., 25: 49-61.

Nirmala K, L Widia, YP Hastuti, W Nurussalam and IA Fauzi, 2020. Physiological response and quality of red tilapia Oreochromis sp. in the culture system using lemna (Lemna perpussila) as phytoremediator. IOP Conf. Ser.: Earth Environ. Sci., 404: 012089.

Puycha K, B Yuangsoi, S Charoenwattanasak, S Wongmaneeprateep, P Niamphithak and P Wiriyapattanasub, 2017. Effect of moringa (Moringa oleifera) leaf supplementation on growth performance and feed utilization of Bocourti's catfish (Pangasius bocourti). Agric. Nat. Resour., 51: 2860291.

Rana KMS, P Biswas and MA Salam, 2020. Evaluation of jute leaf as substitute of fish meal in the diet of mrigal (Cirrhinus cirrhosus) fingerlings. Int. J. Agril. Res. Innov. Tech., 10: 117-122.

Reda RM, RE Ibrahim, El-Nobi G Ahmed and ZM El-Bouhy, 2013. Effect of oxytetracycline and florfenicol as growth promoters on the health status of cultured Oreochromis niloticus. Egypt. J. Aquat. Res., 39: 241248.

Reverter M, N Bontemps, D Lecchini, B Banaigs and P Sasal, 2014. Use of plant extracts in fish aquaculture as an alternative to chemotherapy: Current status and future perspectives. Aquaculture, 433: 50-61.

Ronald N, B Gladys and E Gasper, 2014. The effects of stocking density on the growth and survival of Nile tilapia (Oreochromis niloticus) fry at Son fish farm, Uganda. J. Aquac. Res. Dev., 5: 2.

Roy P, ZM Nadia, MM Hossain and MA Salam, 2021. Tilapia density-dependent cowpea production potential in aquaponics. Egypt. J. Aquat. Biol. Fish., 25: 973-994.

Shourbela RM, WN El-Hawarry, AMA El-Latif and SY Abo-Kora, 2020. Potentiality of Moringa oleifera aqueous extract as a growth modulator and antistress in acute hypoxic Nile tilapia Oreochromis niloticus. Iran. J. Fish. Sci., 19: 67-84.

Srichaiyo N, S Tongsiri, SH Hoseinifar, MAO Dawood, S Jaturasitha, MA Esteban, E Ringo and HV Doan, 2020. The effects gotu kola (Centella asiatica) powder on growth performance, skin mucus, and serum immunity of Nile tilapia (Oreochromis niloticus) fingerlings. Aquac. Rep., 16: 100239.

Stone NM and HK Thomforde, 2004. Understanding your fish pond water analysis report. Cooperative Extension Program, University of Arkansas at Pine Bluff Aquaculture / Fisheries.https://fisheries.tamu.edu/files/2013/09/Understanding-Your-Fish-Pond-Water-Analysis-Report.pdf

Stratev D, G Zhelyazkov, XS Noundou and RWM Krause, 2018. Beneficial effects of medicinal plants in fish diseases. Aquacult. Int., 26: 289-308. 
Toutou MM, AA Soliman, MA Elokaby, RA Ahmed and ES Baghdady, 2018. Growth performance and biochemical blood parameters of Nile tilapia, Oreochromis niloticus, and thinlip mullet, Liza ramada, fed a diet supplemented with lemon (Citrus aurantifolia) peel in a polyculture system. Egypt. J. Aquat. Biol. Fish., 22: 183-192.

Yao J, P Hu, Y Zhu, Y Xu, Q Tan and X Liang, 2020. Lipid-lowering effects of lotus leaf alcoholic extract on serum, hepatopancreas, and muscle of juvenile grass carp via gene expression. Front. Physiol., 11: 584782.

Zang L, Y Shimada, Y Nishimura, T Tanaka and N Nishimura, 2013. A novel, reliable method for repeated blood collection from aquarium fish. Zebrafish, 10: 1-8.

Zhou J, Y Lin, H Ji and H Yu, 2016. The effect of green tea waste on growth and health of grass carp (Ctenopharyngodon idellus). Turkish J. Fish. Aquat. Sci., 16: 679-689. 